\title{
Management of Pheochromocytoma in Dakar: Diagnostic and Therapeutic Advances throughout 16 Cases
}

\author{
Abdoulaye Leye ${ }^{1 *}$, Nafy Ndiaye ${ }^{1}$, Yakham Mohamed Leye ${ }^{1}$, Amadou Fall Cisse ${ }^{1}$, \\ Ngoné Diaba Diack ${ }^{1}$, Michel Assane Ndour ${ }^{1}$, Ameth Dieng', Daouda Thioub', \\ Baidy Sy Kane ${ }^{2}$, Alex Bahati' ${ }^{1}$ Alpha Omar Touré ${ }^{3}$, Cherif Mohamed Dial ${ }^{4}$, Pape Saloum Diop ${ }^{5}$ \\ ${ }^{1}$ Internal Medicine and Endocrinology Department, Teaching Hospital of Pikine Dakar, Dakar, Senegal \\ ${ }^{2}$ Internal Medicine Department, Aristide Le Dantec Teaching Hospital of Dakar, Dakar, Senegal \\ ${ }^{3}$ General Surgery Department, Aristide Le Dantec Teaching Hospital of Dakar, Dakar, Senegal \\ ${ }^{4}$ Anatomo-Pathology Department, General Hospital of Grand Yoff Dakar, Dakar, Senegal \\ ${ }^{5}$ General Surgery Department, General Hospital of Grand Yoff Dakar, Dakar, Senegal \\ Email: *ablayleye@hotmail.com
}

How to cite this paper: Leye, A., Ndiaye, N., Leye, Y.M., Cisse, A.F., Diack, N.D., Ndour, M.A., Dieng, A., Thioub, D., Kane, B.S., Bahati, A., Touré, A.O., Dial, C.M. and Diop, P.S. (2018) Management of Pheochromocytoma in Dakar: Diagnostic and Therapeutic Advances throughout 16 Cases. Open Journal of Endocrine and Metabolic Diseases, 8, 19-28. https://doi.org/10.4236/ojemd.2018.81003

Received: December 19, 2017

Accepted: January 9, 2018

Published: January 12, 2018

Copyright $\odot 2018$ by authors and Scientific Research Publishing Inc. This work is licensed under the Creative Commons Attribution International License (CC BY 4.0).

http://creativecommons.org/licenses/by/4.0/ (c) (i) Open Access

\begin{abstract}
Introduction: Management of pheochromocytoma faces different challenges leading to misdiagnosis and therapeutic delay in developing countries. The aim of our study was to evaluate the diagnostic and therapeutic features as well as the evolution of our management strategies in hospital setting in recent years in Dakar. Patients and Method: We carried out a retrospective study over 12 years (January 2005 to June 2017), in 4 hospitals in Dakar. We only included patients with established diagnosis of pheochromocytoma upon clinical, biological, radiological and histological arguments. Results: During this period, 16 observations have been collected and were all about female patients. The mean age at the time of diagnosis was 36.81 years. The clinical signs were dominated by hypertension found for 14 patients. At biological examination, hypersecretion catecholamine was found in 13 patients, high urinary metanephrines in 7 patients, high plasmatic metanephrines in 2 patients and raised urinary Vanyl Mandelic Acid (VMA) in 4 patients. Dosage of chromogranin A showed high level for one patient. Abdominal CT scan allowed making the adrenal origin of tumors precise. One patient presented bilateral pheochromocytoma. Before being treated surgically, all patients had had medical preparation. The surgical treatment by median laparotomy consisted of an enucleation of the tumor in 2 patients, and adrenal resection in 11patients.The evolution after surgery was favorable in 12 patients out of 13 . One patient died 2 days after surgery by hemodynamic instability. In 2 patients who presented metastases, multidrug
\end{abstract}


therapy with cyclophosphamide, vincristine and dacarbazine was decided after a multidisciplinary meeting, but they died before treatment. Conclusion: Management of pheochromocytomas in developing countries is obviously improving, but the mortality rate remains high. Early diagnosis and perioperative care are to be targeted for better outcome and prognosis of this rare tumor in our areas.

\section{Keywords}

Pheochromocytoma, Diagnosis, Treatment, Dakar

\section{Introduction}

Pheochromocytoma is a rare tumour of adrenal gland's medulla leading to an excessive secretion of catecholamines [1]. Paroxysmal hypertension associated with Menard's triad is the most usual mode of revelation. The first step of the diagnosis consists in highlighting the catecholamine hypersecretion by dosage of the plasmatic or urinary metanephrines [1]. Pheochromocytomas are usually benign tumours; its malignity as for all neuroendocrine tumours is defined by existence of distant metastases [2]. Pheochromocytomas are under diagnosed in occident where $0.05 \%$ to $0.1 \%$ are discovered at the time of autopsies [3] [4]. In Africa, few series had been reported [5] [6] [7]. The aim of our study was to evaluate the diagnostic and therapeutic features of pheochromocytomas in our practice, as well the evolution of our management strategies in hospital setting in recent years in Dakar.

\section{Patients and Method}

We carried out a descriptive cross-sectional study over 12 years (January 2005January 2017). Our study had as a site four teaching hospital centers of Dakar through 2 Internal Medicine departments and 2 General Surgery departments. All folders of patients with confirmed diagnosis of pheochromocytoma upon clinical, biological, radiological and histological arguments, were included. Epidemiologic parameters, clinical and paraclinic data as well as therapeutic and evolutionary features were collected and analysed. As it was an observational study, we didn't face ethical concern.

\section{Results}

During our study period, 16 observations of pheochromocytoma were compiled.

\subsection{Epidemiological Data}

All the patients were female. The average age was 36.81 years with extremes between 12 and 79 years. Twelve patients were old of less than40 years and 7 patients had less than 30 years. All cases of pheochromocytoma were sporadic. 


\subsection{Clinical Data}

Hypertension was found in 14 patients. This hypertension was associated with Menard's triad (headaches, palpitations, sweats) for 5 patients, hypertensive heart disease for three patients and hypertensive retinopathy for two patients. Eight patients presented an abdominal mass. Deterioration of general state in 3 patients and clinical anaemia in 2 patients were also noticed.

\subsection{Paraclinical Data (Table 1)}

- Hypersecretion of catecholamine was objectified in 13 patients. Urinary metanephrines were raised for seven patients as well high serum metanephrines for two patients. Urinary Vanyl Mandelic Acid (VMA) was increased for four other patients. High level of serum chromogranin A was found upon one patient with non-secreting pheochromocytoma.

- Abdominal ultrasound examination showed adrenal mass (Figure 1) in 10 patients.

- CT scan was performed for all patients and allowed to better define features of adrenal tumors and existence of metastasis. Greatest diameters of the tumours varied from 5 to $20 \mathrm{~cm}$ (Figure 2).

One patient presented bilateral pheochromocytoma. Hepatic metastasis associated with a thrombosis of right renal vein was found in one patient. As well, pulmonary metastasis with vascular invasion in one patient, and retro-peritoneal adenopathies in another one were discovered. Thus, three patients respectively 58, 59 and 28-year-old presented arguments for the diagnosis of malignant tumour (Figure 3). None of them underwent MRI or functional imaging.

\subsection{Therapeutical and Evolutionary Data}

All the patients had received medical preparation. For blood pressure control, nicardipine was used in 8 patients and amlodipine in two patients. Labetalol had been used in 3 patients, urapidil associated with bisoprolol in one patient.

Table 1. Distribution of patients according to biological examinations which allowed the description of the secretary syndrome with the standards of laboratory and the average.

\begin{tabular}{|c|c|c|c|c|}
\hline Biological Parameters Units & Normal Range & Extremes Values & Number of Patients & Mean Values \\
\hline Urinary Metanephrines $\mathrm{nmol} / 24 \mathrm{~h}$ & 250 à 1200 & $32-2839$ & 5 & 1331.8 \\
\hline Urinary Normetanephrines $\mathrm{nmol} / 24 \mathrm{~h}$ & 750 à 2000 & $1293-62784$ & 6 & 7847 \\
\hline 3-Methoxytyraminenmol/24 h & 600 à 1300 & $926-6231$ & 5 & 3102.2 \\
\hline Urinary Noradrenaline $\mathrm{nmol} / 24 \mathrm{~h}$ & 90 à 500 & & 1 & 2301 \\
\hline Serum Metanephrines nmol/L & $\leq 0.92$ & $4.32-17.16$ & 2 & 10.74 \\
\hline Serum Normetanephrines nmol/L & $\leq 1.29$ & & 1 & 113 \\
\hline Chromogranin Ang/mL & $\leq 100$ & & 1 & $>100$ \\
\hline Urinary VMA/Creatinine Ratio $\mu \mathrm{mol} / \mathrm{mmol}$ of Creatinine & 0.8 à 2.0 & & 1 & 5.4 \\
\hline Urinary Vanyl Mandelic Acid $\mathrm{mmol} / 24 \mathrm{~h}$ & $<33$ & $100-161.3$ & 4 & 119.95 \\
\hline
\end{tabular}




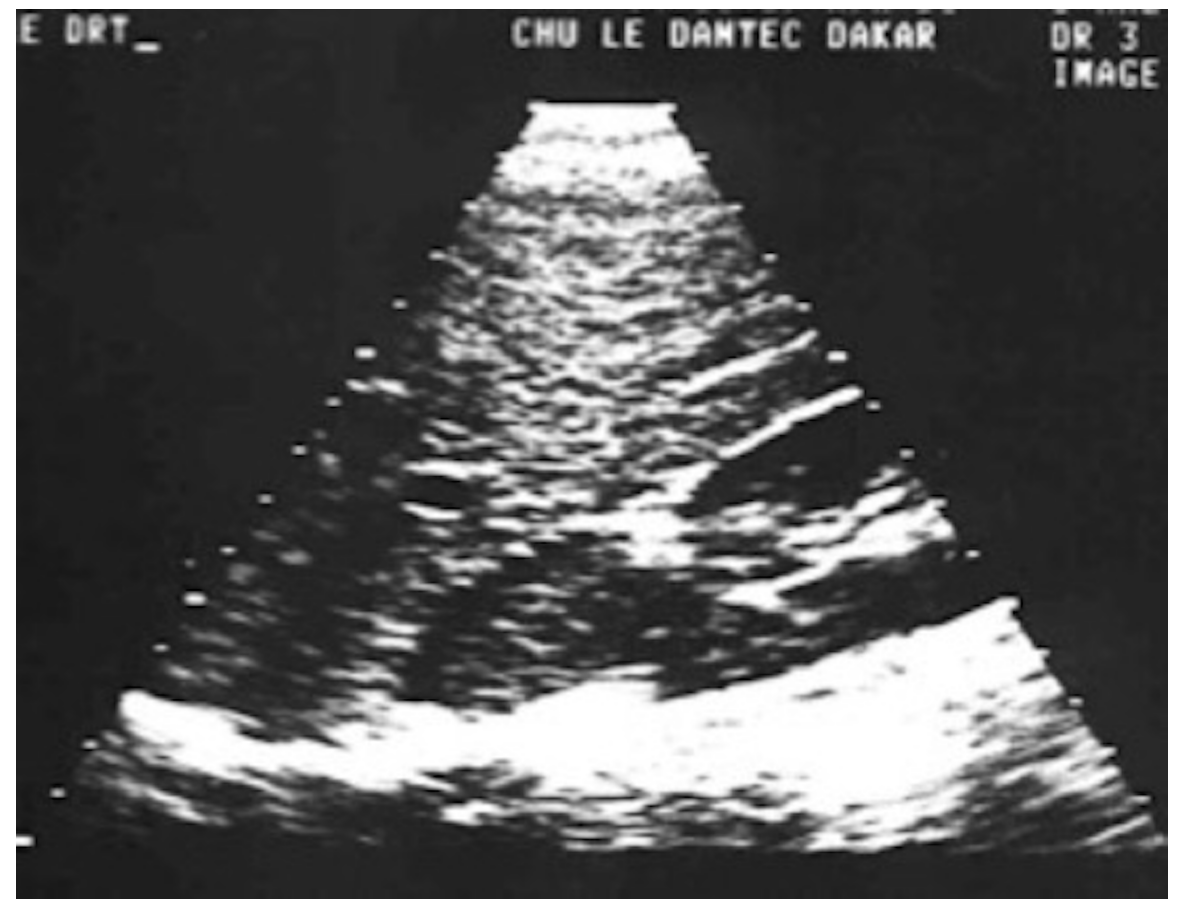

Figure 1. Adrenal mass between the liver and the superior pole of kidney.

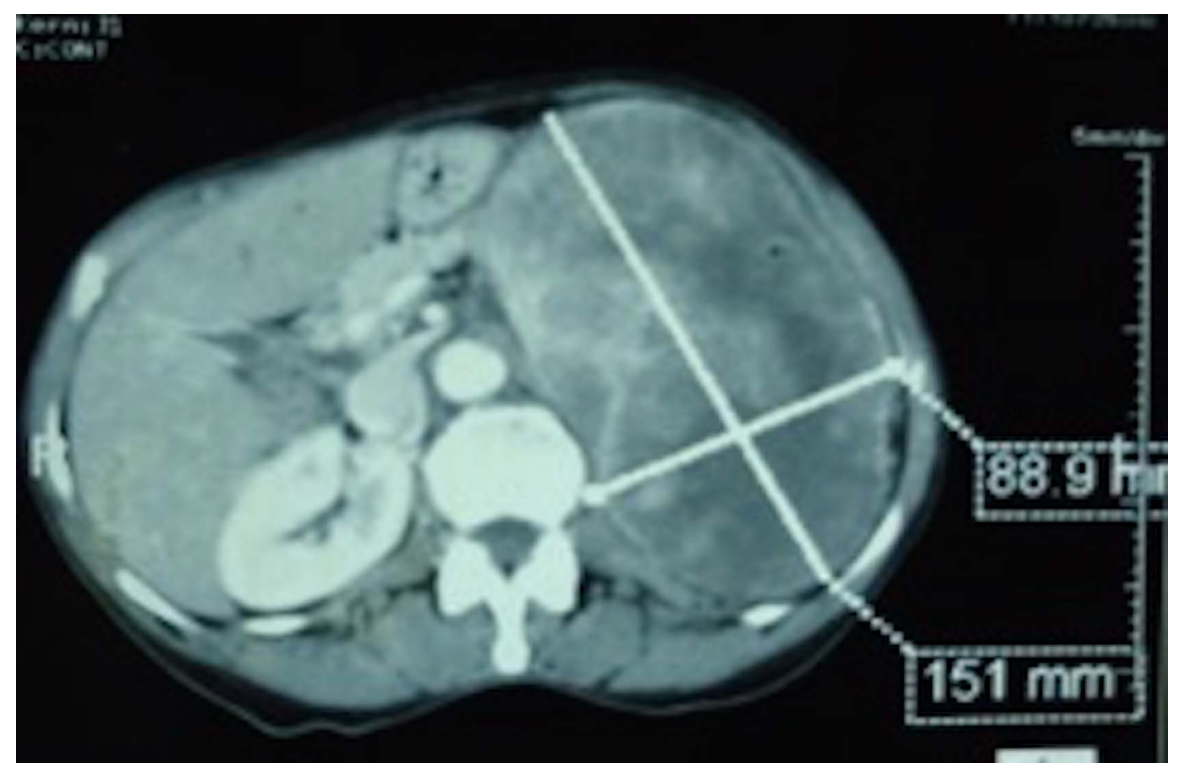

Figure 2. Scan cut of giant pheochromocytoma repelling neighbouring organs.

The surgical treatment was indicated in 14 patients, however one patient died of septic shock before surgery. All surgical procedures were performed by xipho-umbilical laparotomy way. Post-operative evolution was simple for 11 patients out of 13. An enucleation of the tumour was performed in two patients, while 11 others underwent an adrenalectomy (Figure 4).

One patient had presented a post-operative hypertensive push suppressed by a continuous perfusion of nicardipine. No recurrence of hypertension or tumours was noticed for those patients after 2 to 12 months of follow-up. 


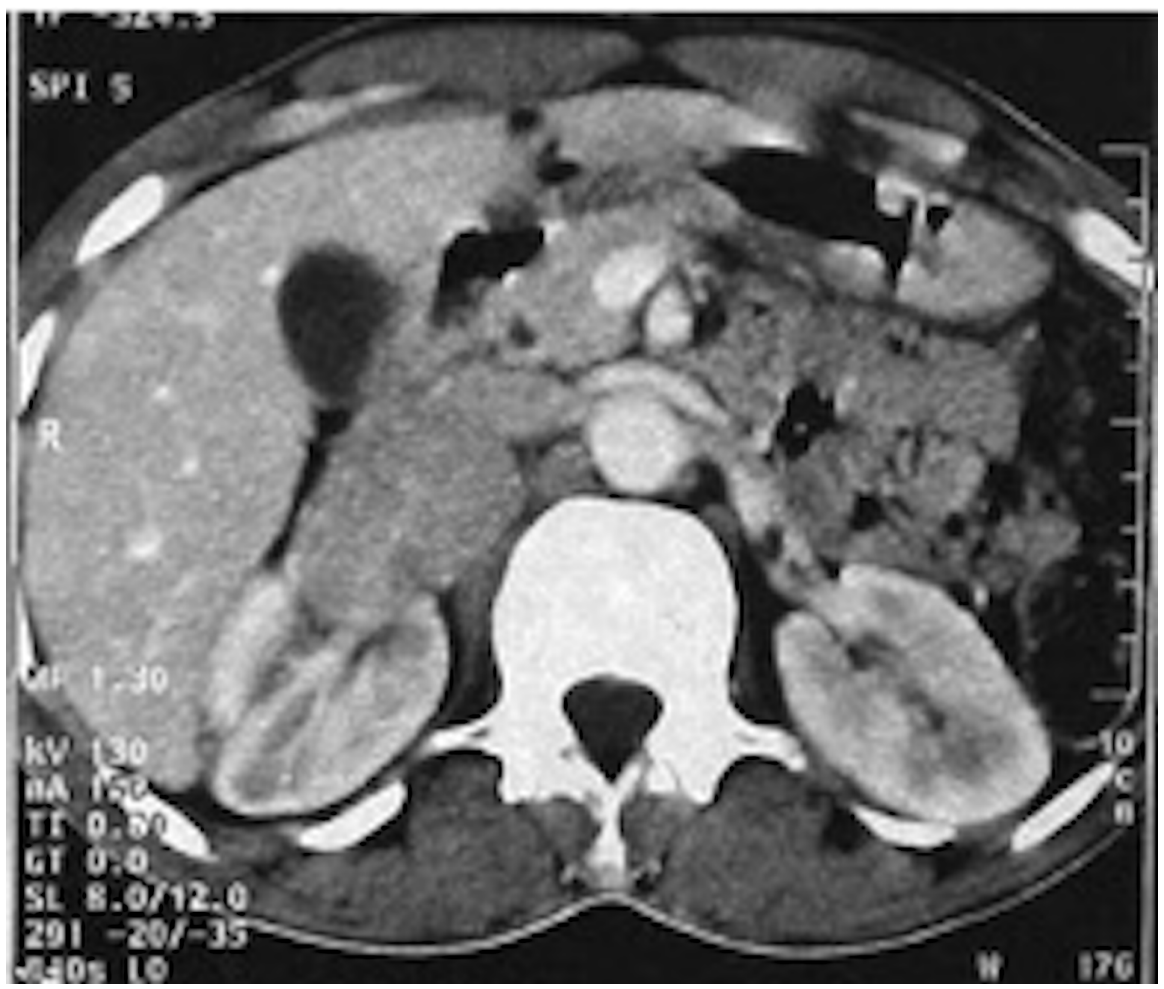

(a)

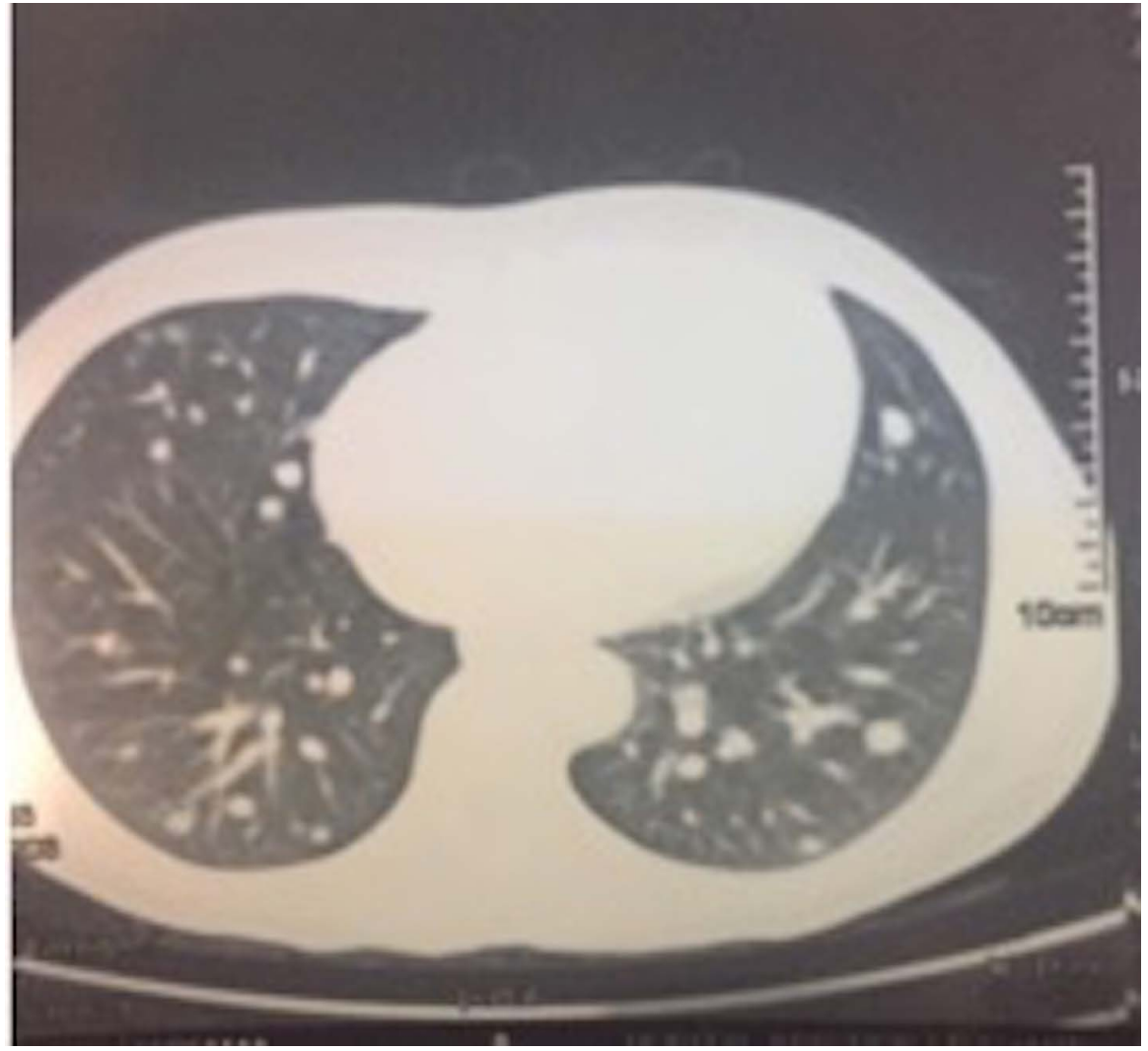

(b)

Figure 3. CT scan cuts in a patient presenting a malignant left pheochromocytoma (a) with pulmonary secondary localizations (b). 


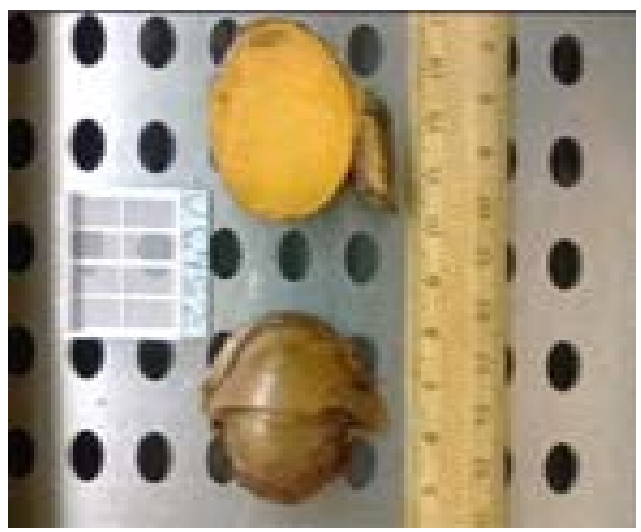

Figure 4. Macroscopic view of resected specimen of adrenalectomy.

One patient died in post-operative period, 48 hours after intervention, by haemodynamic instability. She presented retro-peritoneal adenopathies and her histological examination showed features of malignant pheochromocytoma with PASS score at 4 . For the two other patients with metastasis, multi drug therapy with cyclophosphamide, vincristine and dacarbazine (CVD) was decided after multidisciplinary concertation. One of them died before the beginning of the therapy and the second after the second cure.

\subsection{Histopathological Data}

For all patients who underwent surgery, histopathological examination was performed. Pheochromocytomas were benign, with proliferation of polygonal mononuclear cells and multinuclear cells in 12 patients out of 13 (Figure 5). The last one presented features of probably aggressive malignant pheochromocytoma with PASS score at 4.

\section{Discussion}

The epidemiology of the pheochromocytoma is difficult to establish in Sub-Saharan Africa. It's a rare pathology of probably underestimated frequency. The low prevalence ( 16 cases collected in 12 years) found in our series is also noted in other African series: 9 cases in 17 years between 1981 and 1998 previously reported in Senegal [5], 54 cases in 30 years in South Africa [6], 3 cases in 10 years in Kinshasa [7]. This weak prevalence of the pheochromocytoma in African series may be associated with lake of technological support. However, such weak prevalence is also brought back in developed countries. Indeed, a study conducted in a French Internal Medicine department on a 15 years period with systematic realization of MIBG (Meta-Iodo-Benzyl-Guanidine) scintigraphy among 80 suspected patients of catecholamine hypersecretion had found only 15 cases of pheochromocytoma and 3 abdominal paragangliomas [8]. The average age of our patients around 36 years is in agreement with the data of the literature with a peak of incidence between 30 and 40 years [9]. The female prevalence of the sporadic pheochromocytoma is also known [10]. 


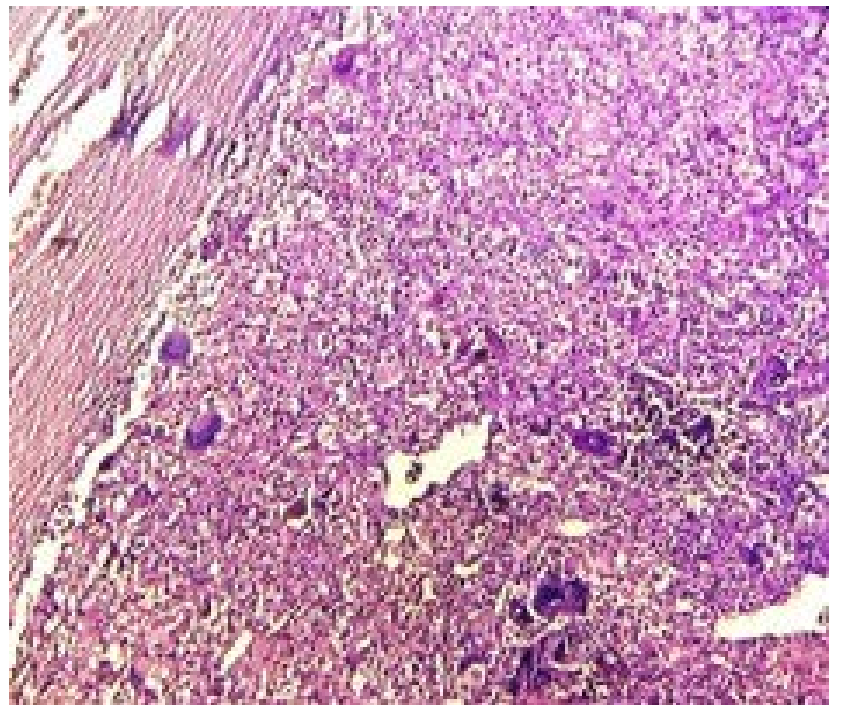

(a)

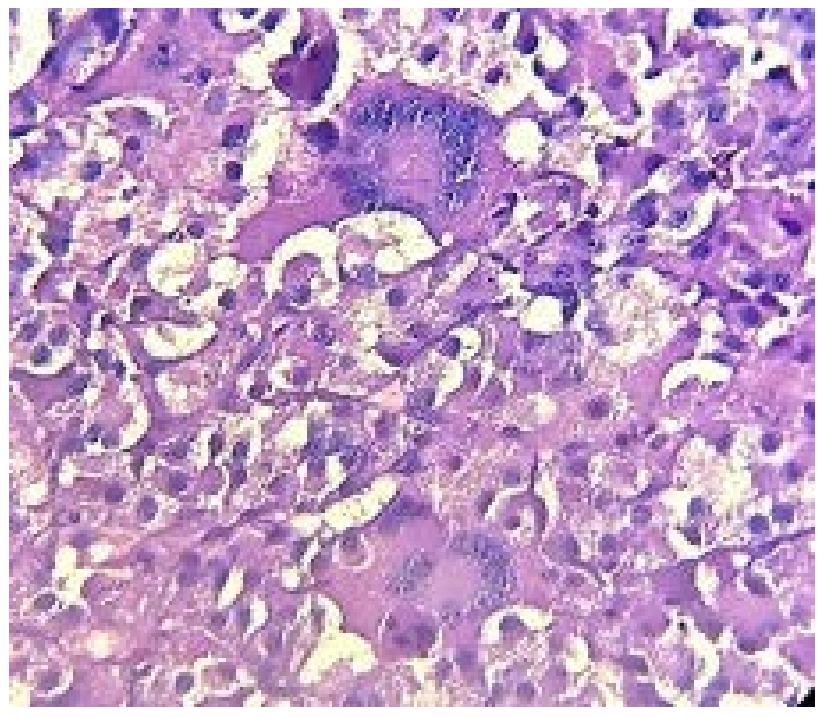

(b)

Figure 5. Histology of pheochromocytoma, with proliferation of polygonal mononuclear cells and multinuclear cells. Hematoxylin-Eosin (HE) Magnification $\times 150$ (a) and $\times 250$ (b).

Clinical manifestations of pheochromocytoma are characterized by its great variability, and lack of specificity [11]. Hypertension is a classical sign specially when it is associated with the Menard's triad; headaches, palpitations and sweats [1] [2] [10] [11]. This typical presentation is found only in $30 \%$ to $40 \%$ of patients [5]. In our series, association of hypertension and Menard's triad were found in 5 patients (31\%) in agreement with the data of literature. In half of our patients there was an abdominal tumoral syndrome seldom brought back in the literature. In the South African study over 30 years, 6 patients out of 54 presented an abdominal tumoral syndrome [6].

A quarter of pheochromocytomas are revealed by an adrenal incidentaloma [12]. The cardiac symptoms of the pheochromocytoma are the consequence either of the repercussions of hypertension, or of the prolonged catecholaminergic impregnation. These complications can appear as left ventricular hypertrophy, cardiac rhythm disorders, dilated cardiomyopathy or even a cardiogenic shock [11]. Coronary syndromes were had been also reported [11] [13]. A hypertensive heart disease was noted in 3 of our patients.

In the event of clinical suspicion of pheochromocytoma, the diagnosis rests on the dosage of the urinary 24 hours or plasmatic methoxylated derivatives [1] [2] [3] [4] [10]. The proportioning of the urinary VMA is not recommended anymore because of its weak sensitivity [14]. At the beginning of our studies the dosage of VMA was the most available and affordable technic and so used in 5 patients. Chromogranin A ( $\mathrm{CgA})$ is a general marker of the neuro-endocrine tumours. This parameter was sometimes the only positive one in front oflittle secreting paraganglioma. It offers an interest because of its excellent negative predictive value around $98 \%$ [15] in the event of negativity of metanephrines' dosage. Dosage of Chromogranin A had been helpful in our asymptomatic patient 
in whom the level of methoxylated derivatives was normal.

CT scan or MRI are major technics for the localization of pheochromocytoma now available in our developing countries. Abdominal ultrasound in the search of pheochromocytoma is no longer recommended [1] [2] [3] [4] and [16]. However, it had allowed the detection of 10 pheochromocytoma in our patients with large tumour and probably delayed diagnosis.

Approximately $10 \%$ to $30 \%$ of the malignant pheochromocytoma are already metastatic at the time of the diagnosis. The most frequent sites of metastases are liver, the lungs, bones and lymph nodes [17]. In our series, all the 3 malignant pheochromocytoma malignant were already metastases at the time of the diagnosis. However, the vascular invasion found in 2 of our patients is seldom reported [18]. The functional imaging could complement the conventional one, in the event of pheochromocytoma of big size (diameter $\geq 5 \mathrm{~cm}$ ), existence of metastases or hereditary predispositions [19]. None of our patients had been explore with functional imaging that is not still available in Senegal by this time.

The treatment of reference of pheochromocytoma is surgery. It must always be realized in an elective way, after premedication aiming to control the blood pressure and to slow down the heart rate, to avoid per-operative complications. Those complications are often due to the extreme blood pressure variability, depending on the secondary discharge of catecholamines with the mobilization of the tumour by the surgeon.

If the blood pressure is not well controlled with alpha blockers treatment, addition of calcic inhibitor is indicated. In case of persistence of tachycardia, beta-blockers should be introduced. But it is necessary to have current and effective alpha blocking treatment [2] [4]. Thirteen patients underwent surgical procedure. This choice seems more judicious since the tumours in our patients having tumours of big size. Indeed, the laparoscopic surgery in the pheochromocytomais indicated for small tumours, lower than $4 \mathrm{~cm}$ in diameter [4]. For the management of the malignant pheochromocytoma, the surgical resection of the primary tumour could decrease the risk of metastases and improve total survival in spite of advanced disease. CVD chemotherapy can be indicated to treat patients presenting an evolutive disease, and the patients who well respond to CVD can gain from a maintaining treatment with the dacarbazine. Clinical trials are ongoing for the use of radio-pharmaceutical agents, inhibitors of tyrosine kinase and immunotherapies [20].

The histological analysis of the tumour does not make it possible to distinguish a benign form from a malignant form of pheochromocytoma. According to the World Health Organization (WHO) classification, the malignity of these tumours is defined by the presence of metastases in an extra paraganglionar site (lymph nodes, bone, liver) [10]. Several scores were established in order to individualize the tumours at risk of malignity, but none makes it possible to establish with certainty the nature of the tumours. Even though not still validated, the most used one is the Pheochromocytoma of the Adrenal gland Scaled Score (PASS), 
of Thompson. This score evaluates 12 histological parameters such as diffuse growth, high cellularity, cellular monotony, a cellular spindle, mitotic figures and others.

However, there is a great variability inter and intra-observer in the evaluation of the parameters making this PAS score difficult to reproduce. A score lower than 4 is in favour of a benign tumour, and higher than 4 is in favour of an aggressiveness [19]. A large tumoral lesion, an extra adrenal localization or a presence of SDHB mutation are of high-risk situations of malignity [19].

Because of potential risk of malignity, it is necessary to control the rate of metanephrines 3 months after surgery and then in an annual way [2]. The mortality of the malignant pheochromocytoma is especially related to the progression of the tumoral mass [15]. Factors of bad prognosis are: existence of hepatic and pulmonary metastases, advanced age and non resectable tumours. The rate of survival at 5 years varies from $24 \%$ to $60 \%$ [17]. All these criteria of bad prognosis were found in our patients with malignant pheochromocytomas.

\section{Conclusion}

Pheochromocytoma remains a rare tumour in our practice but probably under diagnosed. General practitioners and all physicians should be aware of its high probability in case of hypertension associated with Menard's triad. The improvement of the availability and affordability of dedicated diagnostic methods in our developing countries is increasing its frequency and may enhance its global management.

\section{References}

[1] Pappachan, J.M., Raskauskiene, D., Sriraman, R., et al. (2014) Diagnosis and Management of Pheochromocytoma: A Practical Guide to Clinicians. Current Hypertension Reports, 16, 442. https://doi.org/10.1007/s11906-014-0442-Z

[2] Loosli, N., Köhler Ballan, B., Pechère-Bertschi, A., et al. (2014) Pheochromocytoma and Paraganglioma: Basics for the General Practitioner. Revue Médicale Suisse, 10, 1650-1655.

[3] Lenders, J.W.M., Duh, Q.Y., Eisenhofer, G., et al. (2014) Pheochromocytoma and Paraganglioma: An Endocrine Society Clinical Practice Guideline. The Journal of Clinical Endocrinology \& Metabolism, 99, 1915-1942. https://doi.org/10.1210/jc.2014-1498

[4] Davison, A.S., Jones, D.M., Ruthven, S., Helliwell, T. and Shore, S.L. (2017) Clinical Evaluation and Treatment with Phaeochromocytoma. Annals of Clinical Biochemistry, 55, 34-48.

[5] Leye, A., Pouye, A., Fall, B., et al. (2003) Pheochromocytoma in Dakar: About 9 Observations. Dakar Medical, 48, 77-81.

[6] Huddle, K.R.L. (2011) Phaeochromocytoma in Black South Africans-A 30-Year Audit. South African Medical Journal, 101, 184-188. https://doi.org/10.7196/SAMJ.4320

[7] Bieleli, E. and Kandjingu, K. (1990) The Pheochromocytoma: Diagnosis of 3 Cases (from 14 Suspiscions). Medecine d'Afrique Noire, 37, 338-341.

[8] Noblet-Dick, M., Grunenberger, F., Brunot, B., Jaek, D. and Schlienger, J.L. (2003) 
Pheochromocytoma in Internal Medicine: Distinctive Features and Place of 123I MIBG Scintigraphy. La Revue de Medecine Interne, 24, 358-365. https://doi.org/10.1016/S0248-8663(03)00074-2

[9] Garnier, S., Réguerre, Y., Orbach, D., et al. (2014) Pediatric Pheochromocytoma and Paraganglioma: An Update. Bulletin Du Cancer, 101, 966-975.

[10] Laboureau, S. and Rohmer, V. (2014) Pheochromocytoma et paraganglioma. EMC Endocrinologie-Nutrition, 11, 1-11.

[11] Luca, F., Holl, N., Vinzio, S., et al. (2009) Cardiac Manifestations of Pheochromocytoma. Annales of Endocrinology, 70, 43-47. https://doi.org/10.1016/j.ando.2008.11.002

[12] Fall, C.A., Dupuy, O., Garcia, C., et al. (2013) Asymptomatic Secretory Phaeochromocytoma: The Interest of a Systematic Evaluation of Adrenal Incidentalomas. Presse Medicale, 42, 1145-1147. https://doi.org/10.1016/j.lpm.2012.09.020

[13] El Bouazzaoui, A., Hammas, N., Houari, N., et al. (2015) Acute Coronary Syndrome: A Mode Revelation of Pheochromocytoma. Pan African Medical Journal, 22, 151. https://doi.org/10.11604/pamj.2015.22.151.7505

[14] D’Herbomez, M., Rouaix, N., Bauters, C. and Wémeau, J.L. (2009) Biological Diagnosis of Pheochromocytomas and Paragangliomas. Presse Medicale, 38, 927-934. https://doi.org/10.1016/j.lpm.2008.08.011

[15] Amar, L., Lorthioir, A., Giavarini, A., et al. (2014) Presentations and Management of Adrenal Hypertension. Presse Medicale, 43, 420-427. https://doi.org/10.1016/j.lpm.2013.06.032

[16] McDermott, S., McCarthy, C.J. and Blake, M.A. (2015) Images of Pheochromocytoma in Adrenal Glands. Gland Surgery, 4, 350-358.

[17] Noto, R.B., Pryma, D.E., Jensen, J., et al. (2017) Phase 1 Study of High-Specific-Activity I-131 MIBG for Metastatic and/or Recurrent Pheochromocytoma or Paraganglioma. The Journal of Clinical Endocrinology \& Metabolism.

[18] Brauchlin, A.E., Rudiger, A., Bächli, E.B. and Schmid, C. (2009) Portal Vein Thrombus and Liver Failure in a Patient with Pheochromocytoma Crisis. American Journal of Emergency Medicine, 27, 630.e3-630.e5.

[19] Dhir, M., Li, W., Hogg, M.E., et al. (2017) Clinical Predictors of Malignancy in Patients with Pheochromocytoma and Paraganglioma. Annals of Surgical Oncology, 24, 3624-3630. https://doi.org/10.1245/s10434-017-6074-1

[20] Jimenez, P., Tatsui, C., Jessop, A., et al. (2017) Treatment for Malignant Pheochromocytomas and Paragangliomas: 5 Years of Progress. Current Oncology Reports, 19,83 . 